\title{
Políticas de Segurança Urbana e Tolerância Zero na Itália ${ }^{1}$
}

\section{Giuseppe Ricotta²}

\section{Resumo}

Assim como aconteceu em outros países ocidentais, na Itália também o tema da segurança e de sua conexa percepção por parte dos cidadãos assumiu um papel central no debate público. A resposta que as instituições têm dado a esta pergunta, seja em termos retóricos ou práticos, se ressentiu dos efeitos da politização desta questão, desejável para a mídia e para os políticos, e sujeita a dinâmicas típicas do populismo. A especificidade italiana, nos últimos 20 anos, está no papel desempenhado pelos Municípios, e em particular pelos prefeitos, na construção do tema segurança urbana. Este último foi declinado seja em termos de programas de prevenção, e pelo melhoramento da qualidade de vida e do decoro urbano, seja em termos punitivos, com referências ao slogan da "tolerância zero". 0 ano de 2007, sob a onda de uma série de brutais delitos ocorridos em Roma, foi decisivo para 0 sucesso de leituras de tipo alarmista e emotivo, não de todo libertas de tons xenófobos. Justo nessa conjuntura ampliou-se a dificuldade de um discurso autônomo e eficaz sobre segurança urbana de parte da esquerda italiana.

Palavras-chave: Segurança urbana. Políticas públicas. Tolerância zero. Populismo.

${ }^{1}$ Uma versão italiana deste artigo foi publicada em La Rivista delle Politiche Sociali. 1/2012. Tradução do italiano para o português feita por Fabiana Marion Spengler e Luthyana Demarchi de Oliveira.

${ }^{2}$ Ricercatore confermato e Professore aggregato di Sociologia presso l’Università Sapienza di Roma, Dipartimento di Scienze Sociali ed Economiche. Insegna Sociologia dell'Inclusione e della Sicurezza Sociale nel corso di laurea in Scienze e Tecniche del Servizio Sociale. É docente del Dottorato di Ricerca in Sociologia e Scienze Sociali Applicate. giuseppe.ricotta@uniroma1.it 


\title{
URBAN SECURITY POLICIES AND ZERO TOLERANCE IN ITALY
}

\begin{abstract}
:
As happened in other Western countries, in Italy too the issue of the perception of security and the related demand of security by citizens has assumed a central role in the public debate. The answer that the institutions have given to this question, either in rhetoric or practical, has suffered the effects of the politicization of this issue, desirable for the media and politicians, and subject to typical dynamics of populism. Italian specificity is in the role played in the last twenty years by local governments, and in particular by mayors, in the construction of urban security theme. The latter, was declined either in terms of new prevention programs, improving the quality of urban life and the city itself, or in punitive terms, referring to the slogan of "zero tolerance". The year 2007, under the wave of a series of brutal crimes that happened in the city of Rome, was decisive for the success of the second of these two readings, alarmist and emotive, not entirely free from xenophobic tones. With this juncture, Italian left wing showed its difficulty in building an autonomous and effective discourse about urban security.
\end{abstract}

Keywords: Urban security. Public Policies. Zero tolerance. Populism.

\section{Sumário}

1. Introdução. 2. Políticas de Segurança e Populismo. 3. A Segurança Urbana na Itália. 4 A Segurança de Emergência e a Tolerância Zero. 5. Conclusões. Referências 


\section{INTRODUÇÃO}

Nos países ocidentais assistiu-se nos últimos 30 anos a um processo de convergência das práticas e - sobretudo - das retóricas no campo das políticas de segurança. Em particular, foram afirmadas duas estratégias, ambivalentes, de contraposição ao crime (Garland, 2001): de um lado políticas neoconservadoras reativas, essencialmente expressivas e populistas, que prometem certeza e aperto das penas, tolerância zero nos confrontos não só dos delitos da criminalidade difusa, mas também dos comportamentos "incivis" e de degradação urbana (Wacquant, 1999); de outro lado - em resposta às crises fiscais e de eficácia do sistema penal - políticas neoliberalistas adaptativas, de "crime prevention and community safety" (Crawford, 2009; Lucianetti, 2011) que pretendem ativar os recursos não estaduais e extrapenais, trâmites partnership locais e governance multinível, alianças público-privadas, ativação comunitária e cidadania ativa, segundo critérios de economia, subsidiariedade, responsabilização e reafirmação (Selmini, 2004; Battistelli, 2011). Garland (2000) definiu estas duas estratégias, respectivamente, "sovereign State strategy" e "adaptative strategy".

$\mathrm{O}$ caso italiano é aqui analisado à luz desta tendência internacional e nas suas especificidades: na recente história italiana, e no período de 2007 a 2009 em particular, se afirmou um discurso público sobre segurança que uniu a retórica da tolerância zero ao emergente discurso sobre segurança urbana local. Isto favoreceu, na prática, intervenções reativas de forte caráter simbólico e de traços populistas.

\section{POLÍTICAS DE SEGURANÇA E POPULISMO}

O vínculo entre populismo e as políticas de segurança foi analisado, entre outros, pelo criminólogo/sociólogo David Garland (2000, 2001), no contexto das transformações ocorridas no setor penal e na cultura do controle dos Estados Unidos e da Grã-Bretanha nos últimos trinta anos. 
Segundo Garland, em particular, registrou-se um declínio do ideal de reabilitação, ou seja, um colapso da confiança para as políticas corretivas do sistema penal, consideradas incapazes de fazer diminuir as taxas de criminalidade, em constante crescimento dos anos 60 aos anos 90 nos países industrializados. Estas situações teriam favorecido uma maior propensão para discursos e políticas punitivas, que se desviam dos grandes princípios de racionalização e de civilização que regularam os processos da modernização, para refazer as instâncias expressivas arcaicas e fundamentalmente antimodernas (Garland, 2001).

O crescimento dos delitos é explicado pelo aumento das oportunidades de cometimento dos crimes, o que é diretamente relacionado às consequências dos processos de modernização (Giddens, 1990). Entre estes, Garland destaca que a produção em massa, o boom consumista, a diminuição das formas de controle social informal nas casas e nos bairros (por exemplo, a causa da participação no mercado de trabalho de mulheres e homens), o aumento das populações de "risco", por exemplo os jovens adolescentes masculinos, filhos do baby-boom dos anos 50 (com uma participação tardia no mercado de trabalho, mais tempo livre, difusão da cultura do loisir e menos controle da parte dos genitores) e uma difusão dos espaços sociais mais extensos, anônimos e menos controláveis (urbanização e periferia degradadas, mobilidade fundada sob o uso do automóvel privado, etc.).

Se os processos de modernização contribuíram para aumentar o bem-estar e a liberdade individuais, ao mesmo tempo, segundo Garland, deram aos políticos conservadores uma importante chance: utilizar politicamente a angústia crescente para a mudança social e a crise dos valores tradicionais - dramatizada pelo aumento dos delitos - presente em uma parte relevante da opinião pública e especialmente na classe média. A proposta neoconservadora, hostil ao assistencialismo do Welfare State e 
seus custos, à permissividade, ao desperdício de recursos públicos para assistidos "não merecedores", pode assim relançar no campo penal os princípios de lei e ordem. ${ }^{3}$

A preocupação pelo crime, nesta leitura sociológica, é interpretada seja como consequência das dinâmicas das taxas e dos tipos de criminalidade, seja dentro de um geral e mais complexo sentido de incerteza imputável às profundas alterações sociais tardias-modernas (observar também em Bauman, 1999). Consequentemente, a issue segurança floresce dos confins dos especialistas e das "street level bureaucrats" (Lipsky, 1980) do setor penal (forças de ordem, assistentes sociais e staff penitenciário, juízes e Ministério Público), e torna-se um tema significativo para o consenso político, sobre o qual se joga uma parte importante das competições eleitorais.

E o político, seguindo a lógica da maximização do consenso, escolhe retóricas e práticas de segurança com base na sua saída do público: diante de específicos eventos criminais que conquistam atenções dos meios de comunicação de massa, lhes será oportunisticamente trazido e assegurado os humores da opinião pública "midiática”, ou seja, das representações da "voz da estrada" construída nas mesmas mídias (Ortega, 2009). O que se traduz, primeiro, em demonstrar empatia com o sofrimento da vítima e dos seus familiares, símbolo de gente comum, e de uma comunidade

\footnotetext{
${ }^{3}$ Se as políticas neoconservadoras são, portanto, interpretadas como uma resposta à crescente insegurança no crime e à “desordem social”, ao mesmo tempo o surgimento de políticas neoliberais no campo econômico tem sido identificado como a causa de um ressurgimento da insegurança social, relacionado com a crise do Welfare State e a precarização do mercado de trabalho (Castel, 2003). Robert Castel, em particular, tem enfatizado a relação estreita entre o ressurgimento das inseguranças sociais e a nova ênfase sobre o que ele chama "segurança civil", o que tem a ver com a segurança física da pessoa e a protecção de seu patrimônio.
} 
inteira. Nos confrontos do réu, ao contrário - segundo a lógica do jogo de soma zero - a linguagem política exprime desdém, raiva, ressentimento, severidade, tolerância zero. ${ }^{4}$

Estas respostas reativas da política negam a crise fiscal e de legitimidade do Estado penal, e reafirmam o mito do Estado soberano, prometendo mais cárcere e mais polícia; uma sovereign State strategy que Garland define como populista.

Se não é possível individualizar uma definição consensual do populismo, todavia se pode isolar alguns tratados que caracterizam a ideologia de fundo e o estilo. Para tal fim, faz-se referência à revisão crítica de Zanatta (2001) sobre os trabalhos de Taggart (2000), Mény e Surel (2001) e Hermet (2001). A ideologia do populismo é rastreável no apelo ao senso comum, feito diretamente ao povo, depositário exclusivo da virtude contra a gestão oligárquica do poder, e essencializado em uma comunidade orgânica, e também imaginária; o estilo, expressivo e geralmente encarnado em uma leadership carismática, "viola as convenções, simplifica os problemas, exibe certezas sobre as soluções” (Zanatta, 2001, p. 270).

As políticas reativas, descritas por Garland, caracterizam-se, primeiramente, como respostas diretas dos pedidos do povo, da gente comum (forçando, se necessário, as regras formais da democracia representativa, do constitucionalismo e da divisão dos poderes, ou a racionalidade a respeito dos objetivos dos burocratas e especialistas), mas especificamente

\footnotetext{
${ }^{4} \mathrm{Na}$ sociedade tardia-moderna, a construção social do criminoso é ambivalente: em vez que o "desviante", dos quais devem ser estudadas e compreendidas as razões psicológicas e sociais a fim de intervir com programas públicos de recuperação e reintegração, o criminoso torna-se como um ator "racional" e, ao mesmo tempo, como um "monstro". "Racional", de acordo com as "criminologias da vida diária” (Garland, 2001), que interpretam o criminoso como um ator que atua para maximizar o seu prazer em um contexto caracterizado por controle leve e/ou penas não suficientes para desincentivar-lhe; "monstro", de acordo com as "criminologias de vingança" dos anos 70 (Melossi, 2002), que interpreta o criminoso como pessoa malvada e inferior, que ameaça a ordem moral da sociedade, a ser defendida a todo custo, contra qualquer projeto de correcção e "sociologismo."
} 
a estratégia política reativa no tema da segurança é definida em termos populistas cada vez que se endereça, mais que aos cidadãos de uma democracia, aos membros de uma comunidade de vítimas potenciais (Ceretti, 2004). No que diz respeito, depois, ao estilo populista, o tom emotivo da linguagem política tardia-moderna sobre segurança, quente e indignado, severo nos confrontos dos criminosos (apostrofado de tempos em tempos como bestas, animais, monstros) bem além dos confins do "politicamente correto", passou a fazer parte do processo de "policy".

Se a desocupação estrutural e a crise do Welfare, assim como a imigração acelerada e uma urbanização “sem alma” (Castel, 2003) golpearam com profundidade as seguranças dos amplos estratos das populações nas sociedades tardia-modernas, é plausível que estes mesmos tornaram-se mais sensíveis, em uma fase anômica, às propostas populistas (Zanatta, 2001).

\section{A SEGURANÇA URBANA NA ITÁLIA}

Também na Itália, na metade dos anos 90, tem havido uma descontinuidade nos discursos e nas práticas de segurança, que se seguiu, com ao menos um decênio de atraso, os argumentos e estratégias já estabelecidos nos Estados Unidos, na Grã-Bretanha e em outros Estados europeus.

Primeiro, registrou-se a passagem de uma narração sobre segurança centrada principalmente na luta contra o terrorismo político e a Máfia, a uma outra centrada tanto sobre a microcriminalidade (renomeada - significativamente - "criminalidade difusa”), quanto sobre a decadência urbana e sobre o emergente tema da percepção de segurança e de alarme social. O atraso com que a questão da emergente criminalidade difusa conquistou espaço político na Itália, se comparado com outras sociedades ocidentais, pode ser explicado pelas especificidades do contexto italiano: a presença histórica do crime organizado da Máfia - que, depois da fase 
de massacre terminou nos primeiros anos 90 , percorreu estratégias criminais menos visíveis - e a temporada dos "anos de chumbo" do terrorismo político, terminou ao fim dos anos 80 (Battistelli, 2008; Melossi; Semini, 2009). ${ }^{5}$ Entre os primeiros protagonistas de uma nova narrativa sobre questões de segurança estão as autoridades locais do Centro e, especialmente, no Norte da Itália, que por primeiro sentiram a necessidade de responder à "nova” pergunta de segurança dos cidadãos governados por eles, reivindicando um papel no campo das políticas de segurança urbana (Selmini, 2004). O conceito de segurança urbana, de fato, não corresponde àquele de ordem pública de competência estadual, ao menos em dois aspectos: 1) contextualiza o tema da segurança em âmbito local, enfatizando a ideia de governança multinível e de políticas integradas, com o envolvimento de diferentes "produtores de segurança” (as forças policiais nacionais, polícia local, serviços públicos locais, terceiro setor, empresas privadas), e 2) tematiza também fenômenos não criminais ou na fronteira de comportamentos ilegais que também podem influenciar na percepção de segurança nas cidades (de acordo as hipóteses de "incivilidade”), entre as quais pichações, os atos de vandalismo, os ruídos noturnos, o abandono do espaço verde, as estradas danificadas - até comportamentos como uso

\footnotetext{
${ }^{5}$ A mudança no discurso político sobre a segurança segue outros fenômenos importantes, como a crise fiscal do Estado e a crise de legitimidade política do pós-“Tangentopoli” (as investigações da magistratura sobre a corrupção política no início dos anos 90), a mudança demográfica também devido ao processo de imigração, o advento ao governo do país de novas forças políticas "pós-constitucionais" (ou que não tenham participado na fase de elaboração da Constituição italiana após a Segunda Guerra Mundial) e com fortes traços populistas, como "Forza Italia" (o partido político de Silvio Berlusconi) e "Lega Nord”. Com relação ao crime, a Itália seguiu caminhos semelhantes as outras sociedades tardia-modernas. Em particular, existem dois períodos em que se verificou um aumento significativo dos crimes, especialmente contra a propriedade: na década de 70 e início dos 90. Só no último caso um aumento de crime é seguido por um aumento do alarme social (Melossi; Selmini, 2009).
} 
de drogas ou bebidas alcoólicas em lugares públicos, a prostituição de rua, a mendicidade. ${ }^{6}$ Neste sentido, a abordagem de segurança urbana retoma as ideias da broken windows theory (Wilson; Kelling, 1982). ${ }^{7}$

É sobretudo nas experiências de administração do governos locais setentrionais guiados pela esquerda que se experimentam projetos de uma nova prevenção alternativa e subsidiária das tradicionais políticas nacionais penais (Martin; Selmini, 2000). ${ }^{8}$ Após esta fase de tradução experimental dos princípios de segurança urbana por parte de alguns governos locais italianos, e um desinteresse substancial por parte do governo central sobre o tema, no final dos anos 90 a questão segurança entra para as agendas políticas locais, em que os prefeitos - desde 1993 eleitos diretamente pelos cidadãos - reclamam espaço e visibilidade na arena política de segurança e

${ }^{6}$ Ao mesmo tempo, o conceito exclui da sua definição crimes de baixa visibilidade, como algumas atividades típicas do crime organizado, a violência doméstica, ou o chamado crime do colarinho branco, uma vez que visa a abranger em uma única definição, fenômenos que - embora diferentes uns dos outros - são caracterizados por uma visibilidade social alta e, portanto, pode aumentar a sensação de insegurança dos cidadãos.

${ }^{7}$ De acordo com os dois criminologistas neoconservadores, se quebrou o vidro da janela de um edifício, e que não é reparado rapidamente, em breve todas as outras janelas serão quebradas. Isso quer dizer que, em geral, se nada for feito para restaurar o decoro urbano violado por atos de vandalismo, cidadãos, interpretando esses sinais como a ausência de instituições e sentindo-se mais inseguros para isso, eles serão desencorajados a entrar em certas áreas e cuidar de seu bairro, ao contrário do que vai acontecer com os criminosos, que irão interpretar os sinais de incivilidade como um incentivo para cometer um crime sem serem controlados. Estes princípios inspiraram a "tolerância zero" de Rudolph Giuliani, prefeito de Nova York 1994-2001: uma abordagem punitiva contra o comportamento "incivil”, mesmo na ausência de uma infração penal (por exemplo, perturbadora mendicância, pichações, etc.), considerado culpado de má segurança urbana e incentivar o surgimento de crimes mais graves (para uma crítica, ver Wacquant, 1999).

${ }^{8}$ Entre 1994 e 1999, acima de tudo são realizadas intervenções de prevenção "situacional" por meio de decretos dissuasivos ou repressivos de comportamentos específicos, vigilância reforçada das forças policiais locais e da vigilância por vídeo, intervenções de impedimento urbano; presentes - ainda que em menor medida - também experiências de prevenção "social", geralmente realizadas pelas secretarias municipais de políticas sociais (Martin; Selmini, 2000). 
nacionais e o novo fenômeno da imigração é compreendido principalmente em termos emergenciais de segurança e defesa da comunidade (Dal Lago, 1999; Franceschetti, 2011).

A questão da segurança ocupou um lugar importante nos programas eleitorais dos partidos na eleição de 2001. Por exemplo, no "contrato com os italianos", exibido durante o programa TV "Porta a Porta”, Silvio Berlusconi, líder da "Casa delle Liberta" (Casa das Liberdades), coloca como segundo ponto de seu desempenho com os eleitores um "plano para a defesa dos cidadãos e de prevenção de crimes”, mediante a introdução do instituto do "policial ou guarda ou vigia do quarteirão" na cidade, e a promessa de uma redução significativa no número de crimes. Com relação às autoridades locais, após o primeiro protocolo de segurança ser assinado em Modena, em 1998, foram assinados até 2006 mais de 250 protocolos de entendimento entre capitais e "prefetture" (corpo monocrático do Estado representando o governo na província) para responder à exigência crescente por parte do governo local na governança de segurança e garantir a cooperação com as administrações do Estado (Antonelli, 2011).

Além de continuar com os acordos interinstitucionais, alguns prefeitos começam a esculpir os espaços de visibilidade nos jornais locais e nacionais por meio de intervenções na questão controversa de segurança urbana. É a temporada dos "sindaci sceriffi” (prefeitos xerifes), administradores locais que chamam as atenções com suas iniciativas para o decoro urbano mediante, por exemplo, o contraste entre a perturbadora mendicância ou a prostituição na rua. Giancarlo Gentilini, prefeito de Treviso de 1994 a 2003, incorporou o espírito da tolerância zero, típico de determinados prefeitos da "Lega Nord", essencialmente interpretado como uma atitude de hostilidade para com a presença, os hábitos e os 
comportamentos dos imigrantes "extracomunitários", ${ }^{9}$ dos acampamentos ciganos, do tráfico de drogas e da prostituição. Famosa a sua decisão, em 1997, em remover os bancos, em frente da estação de Treviso, porque eram frequentados por "negros". ${ }^{10}$

Embora longe de compartilhar dos discursos xenófobos anteriores, também expoentes da centro-esquerda tornam-se protagonistas dos discursos e soluções que recordam as estratégias de tolerância zero de Nova York. Em 2006-2007, durante o segundo governo Prodi (centro-esquerda), a mídia foi particularmente marcante: a construção de um muro em Pádua em 2006, pelo prefeito da centro-esquerda por razões de segurança pública, a fim de separar as propriedades dos residentes de uma rua adjacente, ocupada por imigrantes, e caracterizada pelo comércio de drogas e prostituição; a portaria “anti-rodo” (portaria contra limpadores de para-brisas nos sinais de trânsito) da cidade de Florença, também administrada pela centro-esquerda, em 2007; a ênfase nas questões de segurança por parte do prefeito de Bolonha, Sergio Cofferati, prometendo, entre outras coisas, severidade contra os “writers”. A polêmica que se criou dentro da maioria, do governo de centro-esquerda (Battistelli, 2008), em que alguns prefeitos

\footnotetext{
${ }^{9}$ Entre outros, para relatar muitos eventos locais da Lega Nord, intitulados "Sim à polenta, não ao couscous" para a defesa de tradição "padana” (do Norte da Itália).

${ }^{10} \mathrm{O}$ prefeito de Treviso declarou: "Era um domingo e eu vi na área da estação dezenas de pessoas negras sentadas no parapeito da ponte, outros estrangeiros extra-comunitários sentados nos bancos e bolsas e mochilas penduradas e balançando nos galhos das árvores. No dia seguinte, fui até o prefetto [corpo monocrático do Estado representando o governo na província], porque eu não tolero que Treviso se torne uma terra de ocupação" ("La Repubblica”, 1997). Em 2008, Gentilini explicou, em um discurso para o partido da Lega Nord, sua ideia de tolerância zero: "Eu quero a revolução contra os acampamentos de ciganos. Eu destruir dois acampamentos em Treviso. E agora não há nenhum. Eu quero eliminar as crianças que vão para roubar os idosos. Se Maroni [Ministro do Interior] disse que precisamos de tolerância zero, eu quero tolerância duplo zero" - como ainda - "Eu quero uma revolução contra os centros de telefonia nos quais os clientes comem em plena noite e depois mijam nas paredes: que vão mijar em suas mesquitas!" ("La Tribuna di Treviso”, 2008).
} 
responderam que a segurança "não é de direita nem de esquerda" - reiterando as distâncias das abordagens fracas ou esquivas nos confrontos do tema da criminalidade difusa e da desordem urbana. ${ }^{11}$

Líderes do governo Prodi fazem um discurso próprio que estão na linha com criminologia da vida cotidiana e da responsabilização do réu (Melossi, 2002). O então ministro do Interior, Giuliano Amato, por exemplo, afirma: "Por que se o destinatário de uma atitude grave é alguém que é pequeno, que não pertence às classes superiores, ou é culpa da extorsão, ou é culpa da sociedade, mas nunca é culpa dele?” (La Repubblica, 2007).${ }^{12}$ Além disso, o governo de centro-esquerda promove, dentro da Lei Financeira 296/2006, os pactos chamados de segurança de segunda geração. Estes incluem a possibilidade de celebração de acordos entre o Ministério do Interior e as autoridades locais a fim de estabelecer "programas extraordinários de aumento dos serviços policiais, de socorro técnico urgente e de segurança dos cidadãos”. Em 20 de março de 2007 o Ministério do Interior estabeleceu um acordo com a Associação Nacional Municípios Italianos (Anci) em nome das cidades com áreas metropolitanas, que serviu de ponto de referência para acordos posteriores entre "prefetture" e autoridades locais no assunto de segurança urbana.

\footnotetext{
${ }^{11}$ De acordo com Fabrizio Battistelli (2008), políticos italianos ao longo dos últimos dez anos, diante das questões de segurança, têm oscilado entre dois extremos: alarmismo ou subestimação do problema. Esta segunda atitude, que tende a minimizar o problema de segurança, caracteriza os esquerdistas, mais inclinados a enfatizar as causas sociais de desvio.

${ }^{12}$ Além disso, na mesma entrevista, Amato disse: "Se minha mulher no semáforo é colocada em uma condição que ou você lava o vidro ou é atacada, eu não devo protegê-la? Devo transformá-la em fascista?” ("La Repubblica”, 2007).
} 


\section{A SEGURANÇA DE EMERGÊNCIA E A TOLERÂNCIA ZERO}

O ano de 2007 representa o ano decisivo de afirmação de um discurso de tolerância zero na Itália, ou - como tem sido observado - de uma estratégia de Estado soberano no confronto da criminalidade difusa e da incivilidade (Melossi; Selmini, 2009). Um "catastrófico ano de 2007" para a centro-esquerda italiana (Battistelli; Lucianetti, 2010), incapaz de abordar a questão da segurança, uma vez que se torna "de emergência”. Alguns assassinatos ocorridos em Roma ocuparam as primeiras páginas dos jornais, as aberturas dos telejornais e tabloides televisivos: o assassinato de uma menina na estação Termini, depois de uma briga por motivos banais, a morte de um ciclista próximo ao hipódromo de Tor di Valle, com o objetivo de roubo, a agressão assassina e a violência sexual contra uma mulher perto da estação ferroviária de Tor di Quinto. A característica comum dos três assassinatos - além da desproporção entre o motivo do crime e os danos causados às vítimas - a nacionalidade das pessoas acusadas dos crimes, todos estrangeiros, todos romenos, e no último caso em ordem cronológica, um romeno do acampamento de ciganos perto da Tor di Quinto. A onda emotiva de traços xenófobos teve um papel decisivo na condução da discussão interna e da ação do então governo de centroesquerda, influenciando a campanha eleitoral e as primeiras ações do novo governo de centro-direita (Boccia, 2008). A mudança dos discursos e das práticas se expressaram, de modo claro, em Roma, como revelado pelas pesquisas específicas (Battistelli; Lucianetti, 2010; Galantino, 2010). Se os prefeitos de centro-esquerda, primeiro Francesco Rutelli, em seguida Walter Veltroni, tivessem promovido, no campo da segurança urbana, intervenções de natureza experimental, como a mediação e a prevenção social e comunitária, em áreas periféricas da cidade (Farruggia; Ricotta, 
2010), segundo uma estratégia adaptativa e uma retórica do tipo inclusiva, a segurança de emergência assumiria uma importância nacional, no lugar de uma abordagem populista sobre o tema. ${ }^{13}$

Galantino (2010), analisando os artigos dedicados à questão da segurança em Roma no período de 2007-2009, nos jornais "La Repubblica” e "Il Messaggero", observa que, entre outros fatores, a tendência da notícia dedicada à criminalidade e à segurança não tem seguido as tendências dos crimes na Capital quanto os fatos específicos das crônicas, como no do assassinato de Tor di Quinto e - em 2008 - a campanha eleitoral para a renovação do governo local; também a questão da segurança foi associada ao nome do desafiante do prefeito Veltroni, o atual prefeito Gianni Alemanno (direita), confirmando a "issue ownership" (Gusfield, 1981) do tema, ou seja, a capacidade de influenciar a definição pública, conquistada pela direita em âmbito local e nacional (Cavazza; Corbetta, 2008) e, finalmente, mostrou a alta frequência de referências de "rom" e "nômades" em relação às questões de segurança.

O debate que se seguiu após o assassinato em Tor di Quinto influenciou fortemente o governo Prodi. Pressionado também pelas demandas de vários prefeitos de destaque, o governo emitiu na mesma noite do assassinato uma medida que previa a expulsão imediata dos cidadãos comunitários da prefeitura e seus familiares por razões de segurança pública que os tornavam incompatíveis com a vida comum. Como observado por Pastore (2007), trata-se de uma disposição que comunica aos cidadãos: 1) que existe algo a temer de uma categoria social, o imigrante comunitário, em vez de o autor de um crime específico (ao qual se aplicam ordinárias

\footnotetext{
${ }^{13}$ Veja a declaração após os eventos de Tor di Quinto pelo prefeito Veltroni: “A migração maciça determinada a partir da entrada da Romênia na UE tem sido uma matriz muito diferente: ao lado de muitas pessoas boas existem criminosos demais. Roma - de acordo com todas as estatísticas européias, antes de $1^{\circ}$ de janeiro de 2007 foi a cidade mais segura do mundo. Mas agora..." ("La Repubblica”, 2007, cit. in Galantino, 2010, p. 212).
} 
leis penais), 2) que a expulsão de um número de indivíduos pertencentes à categoria imigrante comunitário (romenos) pode aumentar a segurança do país. ${ }^{14}$

A centro-direita vence as eleições políticas de 2008, também na onda da segurança de emergência, bem como as eleições locais em Roma do mesmo ano. Pouco antes da vitória eleitoral, Silvio Berlusconi resumiu seu programa político de segurança como "Popolo delle Liberta": "Tolerância zero com os ciganos, os clandestinos, os delinqüentes, um não à política de portas abertas e penas mais graves para reincidentes. Introduziremos rapidamente policiais e guardas de quarteirão nas cidade com mais de 15 mil habitantes" (Il Giornale, 2008). A estratégia do recém eleito $4^{0}$ governo Berlusconi encontrou, portanto, uma referência retórica ideal na tolerância zero. A Lega Nord, em particular, pôde reconduzir um único discurso coerente de defesa da comunidade, das políticas punitivas e da segurança urbana. O novo ministro do Interior, Roberto Maroni, voa para os Estados Unidos para discutir sobre segurança com o ex-prefeito Giuliani: "Eu vim para estudar o modelo de segurança urbana de Nova Iorque, com base no conceito de tolerância zero, um modelo que queremos aplicar em todas as cidades italianas” (La Repubblica, 2008). Por sua vez, a centro-esquerda apareceu como inadequada para propor uma visão específica do tema: a falta de uma estratégica política de segurança adequada para a emergência do momento, e com a necessidade de não perder o apoio eleitoral, os

\footnotetext{
${ }^{14}$ A reação pode ser interpretada como acting-out. Após Garland (2001), essas leis podem ser introduzidas na base de uma grande indignação pública, provocada pela prática de crimes violentos tão graves que põem em causa imagens arquetípicas em que estão localizadas, em lados opostos, um criminoso perigoso, malcontrolado, e uma vítima inocente e indefesa, pertencente à classe média.
} 
líderes dos partidos progressistas, perseguiram - tanto em Roma quanto em âmbito nacional - a contrapartida política de esquerda com discursos políticos sobre "repressão" e "tolerância de zero". ${ }^{15}$

O $4^{0}$ Governo Berlusconi traduziu em norma o conceito extrajurídico de segurança urbana, reforçando os poderes de comando dos prefeitos, mas sob o disfarce de oficiais do governo: como órgão local do sistema estatal de ordem e de segurança pública, o prefeito pode tomar medidas não apenas em situações de urgência, a fim de "impedir e eliminar graves perigos que ameaçam a incolumidade pública e a segurança urbana" (reforma do artigo 54 do t.u.e.l, texto único das entidades locais). Foi necessário um decreto posterior do Ministério do Interior ( 5 de agosto de 2008) para explicar o que é a segurança urbana: um bem público a ser tutelado por meio da atividade colocada como defesa, no âmbito das comunidades locais, em conformidade com as normas que regem a vida civil, para melhorar as condições de vida nos centros urbanos, a convivência e a coesão social. Isto por meio do contraste e da prevenção da degradação urbana e do isolamento (que podem impulsionar a venda de drogas, a exploração da prostituição, a mendicância de emprego dos menores e deficientes físicos ou abuso de álcool), os atos de vandalismo, o emprego indevido de propriedade ou terras públicas, o comércio abusivo, enfim, as atividades de prostituição e mendicância mesmo similares, porque podem ofender a decência pública e impedir a livre utilização de espaços urbanos pelos outros cidadãos.

Um ano após a entrada em vigor da medida, das 788 portarias pesquisadas pelas Anci, 69\% foram emitidas pelos municípios do Norte da Itália, e têm como áreas de política prioritárias, em ordem numérica, o

\footnotetext{
${ }^{15}$ A segurança é listada como o primeiro dos dez pilares do programa de governo do Partido Democrático (o principal partido de centro-esquerda) durante a campanha eleitoral de 2008: "Segurança em primeiro lugar. Ser rigoroso contra o crime e os criminosos. Ser rigoroso contra os que fazem violência às crianças”.
} 
consumo de bebidas alcoólicas, a prostituição, o vandalismo, a venda de alimentos/bebidas, o abandono de resíduos, a mendicância, os ruídos, a perturbação da cidade, a falta de estacionamento/camping (Cittalia/Anci, 2009). Fenômenos de marginalização social, tais como a prostituição e a mendicância de rua sofrem um processo de criminalização, pois ofensivo à decência pública e um obstáculo para o livre exercício dos espaços urbanos por parte dos outros cidadãos. ${ }^{16}$

Outras medidas contidas nos chamados pacotes de segurança têm estabelecido a introdução do crime de imigração ilegal, um plano especial de controle e despejos para enfrentar o "estado de emergência em relação aos acampamentos nômades”, a instituição de voluntários de segurança (os chamados "rondas"), o uso da força armada em defesa das cidades italianas de médio e grande portes como tarefa de ordem pública. ${ }^{17} \mathrm{~A}$ maioria destas medidas, adotadas na longa onda de segurança de emergência entre 2008 e 2009 provaram a ineficiência, sob o ponto de vista da legitimidade. ${ }^{18}$

Em 7 de abril de 2011 a Corte Constitucional, na sentença n.115, redimensionou os poderes extraordinários da portaria dos prefeitos, para realocar o nível de ordens urgentes e temporárias; em 16 de novembro de 2011, após três anos da promulgação do chamado Plano de Emergência

\footnotetext{
${ }^{16}$ Ao recordar alguns princípios que são inerentes a broken windows theory, Wilson e Kelling (1982) afirmam que o medo dos cidadãos também é derivado de ser incomodado por disorderly people (pessoas desordeiras), as pessoas não necessariamente violentas ou criminosas, mas pessoas de má reputação, agressivas ou imprevisíveis, como mendigos, bêbados, adolescentes arruaceiros/agitados, prostitutas, vagabundos, doentes mentais.

${ }^{17}$ Esta iniciativa simbolicamente incorpora a mudança no discurso sobre a segurança na Itália: onde em 1992 na operação "Vespri siciliani”, os militares foram enviados para a Sicília para reafirmar a presença do Estado contra a Cosa Nostra (organização mafiosa); no verão de 2008 foram utilizados em patrulhas ou a supervisão de pontos fixos, para tranquilizar os cidadãos contra a criminalidade generalizada.

${ }^{18}$ A discussão em separado, e pesquisas ad hoc, merece o tema da eficácia dessas políticas em relação aos problemas sociais complexos e diversificados, como a prostituição, mendicância, alcoolismo.
} 
Nômade (os acampamentos de ciganos), o Conselho de Estado, mantendo a defesa de uma associação para a defesa dos direitos dos "rom" e de dois residentes do acampamento "Casilino 900" de Roma, reiteraram que não se sustentavam, em 2008, as condições para declarar estado de emergência. No ano anterior, a Corte Constitucional declarou a ilegalidade do uso de "rondas" em uma situação de "angústia social”, sem mencionar as inúmeras ordens municipais contestadas nos Tribunais e consideradas ilegítimas (entre elas a ordem “antilavavetri” de Florença, em 2007). A acusação feita nesses casos pelos políticos de direita para os juízes (para ser politizados ou insensíveis às necessidades de segurança das pessoas), ${ }^{19}$ é a confirmação da natureza populista dessas intervenções: mede-se o valor emocional e simbólico, para os quais o efeito anunciado é um aspecto fundamental na relação entre política e opinião pública dos meios de comunicação, e onde o objetivo da confiança vem antes do aumento dos níveis de segurança objetivo. ${ }^{20}$

\section{CONCLUSÕES}

Temas "quentes" como o de segurança, que envolve sentimentos tais como medo, ressentimento, desconfiança e direitos fundamentais dos cidadãos, incluindo o direito à segurança e à justiça, são especialmente lucrativos durante a campanha eleitoral. E, como destacado por Garland (2001), os argumentos punitivos sobre segurança se alimentam de imagens, arquétipos, propagação de ansiedade pela mídia - fechado a qualquer

\footnotetext{
${ }^{19}$ Em relação ao acórdão do Tribunal sobre as ordenanças, o delegado para a segurança do prefeito de Roma afirmou: "A decisão da Comissão é um tapa. O Tribunal decidiu que as pessoas têm de viver com a prostituição, lava-carros e os bêbados na rua” (Corriere della Sera, 2011).

${ }^{20}$ Mesmo em Roma, o novo prefeito de centro-direita, Alemanno, põe em prática uma série de medidas simbólicas, de acordo com a retórica de tolerância zero, como o recenseamento da população nômade, o decreto contra a prostituição na rua, a demanda por patrulhas militares para proteger alvos sensíveis na cidade (Battistelli; Lucianetti, 2010).
} 
possibilidade compreensão do fenômeno. No caso italiano, como alhures, a relação direta entre a política e a opinião pública dos meios de comunicação foi apoiada pela fragmentação do papel da mediação dos partidos políticos. Nesse sentido, as respostas da política italiana, entre 2007 e 2009, a "emergência de segurança”, é interpretável como uma estratégia reativa, simbólica e populista, no entendimento do Garland. Na ausência de uma reflexão por parte da política, do mundo da informação e dos peritos do modo como a segurança tem sido tratada e explorada eleitoralmente nos últimos anos na Itália, é fácil de prever que os futuros crimes hediondos que têm como vítimas "pessoas comuns", iluminados pelos holofotes da mídia, vamos voltar a assistir à proliferação de discursos punitivos e intervenções reativas, mais simbólicos que eficazes.

As forças políticas democráticas, agora, devem enfrentar a questão de segurança dos cidadãos, especialmente em sua declinação urbana - e são chamados a oferecer estratégias credíveis tanto na luta contra o crime comum quanto no decoro urbano e na qualidade de vida. Para não desembocar na seara populista, a primeira coisa a evitar é a receptividade da proposta de política de emergência: a natureza reativa da proposta política, de fato, gera populismo (Zanatta, 2001). Ao mesmo tempo, é necessário pôr em discussão os elementos antidemocráticos do discurso público sobre segurança, a partir dos acentos xenófobos em que a alegada culpa é de cidadãos estrangeiros ou ciganos. Para se fazer isso o estilo populista de política deve ser controlado. Os políticos italianos, do nível local e nacional, estão prontos a um teste de autocontrole?

\section{REFERÊNCIAS}

ANTONELLI, V. L'esperienza dei "patti per la sicurezza" nel triennio 2007-2009. In: PAJNO, A. (a cura di), La sicurezza urbana. Maggioli: Rimini, p. 133-167, 2011. 
BATTISTELLI, F. La fabbrica della sicurezza. Milano: Franco Angeli, 2008.

BATTISTELLI, F. Sicurezza urbana: il paradosso dell'insicurezza e il dilemma della prevenzione. Rassegna italiana di Sociologia, vol. 52 (2), p. 201-228, 2011.

BATTISTELLI, F.; LUCIANETTI, L. F. La sicurezza tra politics e policy. In: PAJNO, A. (a cura di), La sicurezza urbana. Maggioli: Rimini, 2010. p. 75-110.

BAUMAN, Z. In Search of Politics. Cambridge: Polity Press, 1999.

BOCCIA, M. L. Gli imprenditori politici della paura. Il paradigma della destra per controllare le differenze. Quale Stato?, n. 3-4, p. 184-201, 2008.

CASTEL, R. L'insécurité sociale. Qu'est-ce qu'être protégé? Paris: Seuil, 2003.

CAVAZZA, N.; CORBETTA, P. Quando la difesa del territorio diventa voto. Il Mulino, n. 3, p. 441-448, 2008.

CERETTI, A. Presentazione. In: GARLAND D. La cultura del controllo. Crimine e ordine sociale nella società contemporanea. Tradução italiana Garland, 2001. Milano: Il Saggiatore, 2004. p. 11-44.

CITTALIA/ANCI. Oltre le ordinanze. I sindaci e la sicurezza urbana. Seconda edizione. Roma, 2009

CRAWFORD, A. (a cura di), Crime Prevention Policies in Comparative Perspective, Portland: William Publishing. 2009

DAL LAGO, A. La tautologia della paura. Rassegna italiana di Sociologia, vol. 40 (1), p. 5-41, 1999

FARRUGGIA, F.; RICOTTA, G. Sicurezza urbana e periferie. Due studi di caso a Roma. Aracne/Quaderni di Ricerca del DIeS, Sapienza Università di Roma, Roma, 2010.

FRANCESCHETTI, L. Immigrazione e sicurezza: tra rappresentazione sociale e politiche pubbliche, presentato al Convegno. Immigrazione: inclusione, cittadinanza e legalità. Sapienza Università di Roma, Facoltà di Scienze Politiche, Sociologia, Comunicazione, 14 aprile. 2011. 
GALANTINO, M. G. La società della sicurezza. La costruzione sociale della sicurezza in situazioni di emergenza. Milano: Franco Angeli, 2010.

GARLAND, D. The Culture of High Crime Societies. Some preconditions of Recent "Law and Order" Policies. British Journal of Criminology, vol. 40, p. 347-375, 2000.

GARLAND, D. The Culture of Control. Crime and Social Order in Contemporary Society, Oxford: Oxford University Press, 2001.

GIDDENS, A. The Consequences of Modernity. Cambridge: Polity Press, 1990.

GUSFIELD, J. R. The Culture of Public Problems: Drinking-Driving and the Symbolic Order. Chicago: University Chicago Press, 1981.

HERMET, G. Les populismes dans le monde. Une histoire sociologique. XIXeXXe siècle. Parigi: Fayard, 2001.

"Il Giornale". Berlusconi: il programma dei primi 100 giorni, 11 febbraio 2008.

"La Repubblica”. Fa togliere le panchine: le usano gli immigrati, 15 ottobre 1997.

“La Repubblica”. Basta orrori, è emergenza nazionale, 1º novembre 2007.

"La Repubblica". Maroni: così importerò in Italia la tolleranza zero di New York, 13 dicembre 2008.

"La Tribuna di Treviso". Gentilini shock a Venezia: Vadano a pisciare nelle moschee, 21 novembre 2008.

LIPSKY, M. Street-Level Bureaucracy. New York: Russel Sage Foundation, 1980.

LUCIANETTI, L. F. Crime Prevention and Community Safety Policies from a Dynamic and Comparative Perspective: The Cases of Rome and London. Crime Prevention and Community Safety, vol. 13 (4), p. 260-272, 2011.

MARTIN, L.; SELMINI, R. I progetti per la sicurezza nelle città italiane. Quaderni di Città Sicure, n. 20b, p. 27-36, 2000. 
MELOSSI, D. Stato, controllo sociale, devianza. Milano: Mondadori, 2002.

MELOSSI, D.; SELMINI, R. Modernisation of Institutions of Social and Penal Control in Italy/Europe: The New Crime Prevention. In: Crawford (a cura di), Crime Prevention Policies in Comparative Perspective. Portland: William Publishing, p. 153-176, 2009.

MÉNY, Y.; SUREL, Y. Populismo e democrazia. Bologna: Il Mulino, 2001.

ORTEGA, F. Il populismo dell'opinione pubblica mediatica. Comunicazione pubblica, n. 3, p. 363-381, 2009.

PASTORE, F. Se un delitto fa tremare l'Italia. Come si affronta una security crisis? Italianieuropei, n. 5, p. 19-32, 2007.

SELMINI, R. (a cura di). La sicurezza urbana. Bologna: Il Mulino, 2004.

TAGGART, P. Populism. Buckingham-Philadeplhia: Open University Press, 2000.

WACQUANT, L. Le prisons de la misère. Paris: Éditions Raisons d'Agir, 1999. WILSON, J. Q. KELLING, G. L. Broken Windows. The Police and Neighborhood Society. The Atlantic Monthly, vol. 279 (3), p. 29-38, 1982.

ZANATTA, L. Il populismo. Sul nucleo forte di un’ideologia debole. Polis, vol. 16 (2), p. 263-292, 2001.

Recebido em: 13/9/2012

Aprovado em: 13/9/2012

Autor convidado e artigo não avaliado 